\title{
Analysis on the Moral Value of the Consideration Model for Kindergarten Social Activities
}

\author{
Jijun $\mathrm{Wu}$ \\ Dalian Polytechnic University Arts and Information Engineering \\ Zhuanghe, China
}

\begin{abstract}
The consideration model, based on the main line of "moral feeling", with purpose of "learning to care for others" specifies the operational premise and implementation procedures, and constructs a set of four-dimensional education mode that connects past and future and have logic selfconsistency. This model emphasizes the human temperature of concern and understanding in terms of motivation needs, environmental infiltration, model imitation, and moral education. The value analysis of the consideration model can bring much enlightenment for the kindergarten social activities to break the moral education dogma, update the moral education mode, and return to moral life.
\end{abstract}

Keywords - the consideration model; four-dimensional integration; kindergarten social activities; value analysis

\section{INTRODUCTION}

"Moral" is the foundation of people, and it is also the promised land of education. Throughout the ages, the discussion of the model of moral education has always been a hot topic and focus of the academic circles. The representative ones include cognitive moral education models, value clarification models, the consideration models, and the social action models. These models have different emphasis on moral cognition, moral emotions, moral will and moral actions while the consideration model is unique because it emphasizes the emotional factors in moral education.

\section{THE STRUCTURE OF "FOUR-DIMENSIONAL} INTEGRATION" — A THEORETICAL OVERVIEW OF THE CONSIDERATION MODEL

\section{A. Emerging at the Right Moment: the Beginning of the Consideration Model}

The consideration model was first born in the 1970s. The specific historical background of moral crisis and the raging of intellectualism moral education are undoubtedly the trigger for the formation of the consideration model. On the one hand, a series of realistic social problems such as murder, drug abuse and sexual disorder led to people's reexamination and reflection on morality; on the other hand, the understanding and application of moral cognition model tended to be extreme, and gradually became rigid, so it solidified into a set of stubborn and dogmatic theory that only followed recognition. The declining social atmosphere and the moral education tradition of intellectualism supplied each other, delineating a desolate scene away from life and alienated from humanity. It is undeniable that under the condition where the thinking paradigm of scientism, instrumentalism, intellectualism, and rationalism is going to the extreme, it is necessary to reverse the dilemma by adopting a new and innovative thinking paradigm and moral education model. Therefore, "the consideration model" initiated by Macphail et al. suddenly emerged based on the refutation of the stereotype of old moral education "intellectualism" and the bias of "male chauvinism". "The consideration model" believes that "every morality must be understood and comprehended, instead of being taught."

\section{B. Promoting Morality with Emotion: the Basic Structure of the Consideration Model}

"Model" is "a way of thinking that solves problems" [1], so "establishing a certain model of thinking is to solve a certain type of problem" [1]. At present, there are several definitions of "moral education model": "method category theory", "simplification theory" and "strategic system theory" [2]. Scholar Jing Guangyi believes that the moral education model is "stable and concise structural theory framework of moral education and the specific operational procedures and methods of moral education practice activities [2]. Such definition of moral education model inherits moral education theory and connects moral education practice, highlighting the characteristics of the model, which have reference value. Therefore, this paper uses Jing Guangyi's understanding of the "moral education model" and believes that the moral education model "is not only a stable and concise structural theory framework, but also a practical procedure and method of moral education practice."

If any moral education model is to play a theoretical and practical dual-subject function, it must contain multiple elements that interconnect and coexist with each other and eventually present a system and framework with considerable stability and consistency. As a kind of organically unified moral education system, the consideration model has the basic structure that must be related to the four basic elements of the main line of model construction, the orientation of moral education, the preconditions and conditions of operation, and the implementation procedures and the relationship between them. 
1) The main line of construction of "the consideration model": With the basis and main line of construction of "moral emotion", the consideration model believes that moral cultivation should resort to the "influence". "Moral is influenced rather than directly taught" [3], "Influence" as a way of moral infiltration, with more emphasis on emotional resonance and influence, pays attention to the concealment and potential of moral education curriculum. Macphail said, "The moral education should not be reduced to just analyzing rules and prohibitions, but should motivate the humanity of everyone as a human being, and cultivate an altruistic spirit." [3] Gilligan, Notting Si, Martin and others "together show a new moral model to people, which is to consider the emotional factors in moral growth, and put emotional factors at the center of moral education" [4]. This reflects the refutation of the consideration model to the cognitive moral education and emphasis on the emotional moral education.

2) The target positioning of "the consideration model": The goal of the consideration model is to make people learn to care for and consider others. "The purpose of moral education should be teaching people how to consider and care for others, to learn to love and be loved" [4], and "mature is creative care" [3]. Through long-term investigation and experiment, Mcphail believes that "care and be cared" and "love and be loved" are the basic needs of human beings from the perspective of needs and motivations, and school moral education should shoulder the responsibility to meet and develop this need. He said in the "Lifeline" education series that the purpose of moral education is to "start from the motive and focus on improving the few morality of considering for others in everyone's mind, and continue to expand it." "[5]. He has raised the purpose of "care and consideration" of moral education to the height of the meed of humanity development, which is quite original compared with other moral education models.

3) The operating premise of "the consideration model": The operation and implementation of the consideration model requires certain realistic conditions, which are mainly reflected in the quality of teachers, method selection, and selection of teaching materials. First of all, the consideration model puts forward the requirements for teachers' quality. Teachers need to provide opportunities for the stimulation and awakening of students' moral emotions. They should be good at creating an educational atmosphere of mutual concern and understanding, and use their own moral words and deeds and personality as examples to influence the students by using their respect for teachers. It is undoubtedly a rebellion and innovation of traditional indoctrination moral education. Secondly, in the selection of moral education methods, the consideration model rejects the extremely rationalized moral education method, focuses on the use of situational creation, concealed courses and other methods to organize moral education activities; then, in the selection of teaching materials, the consideration model draws lessons from Dewey's pragmatic education philosophy, and believes that the content of the textbook should be closely related to the students' actual life experience to prevent moral education from changing to "false, big and empty" and unrealistic reverie.

4) Implementation procedures of "the consideration model": The consideration model proposes specific operational moral education procedures and steps to make its theoretical ideas be implemented. "Lifeline" textbooks series and "Learn to Survive" designed by Mcphail and Nottings's "Learn to Care - Another Model of Education" highlight the characteristic moral education program of the consideration model to a certain extent. The procedures for teaching with sensitive cards are more representative, and the operating procedure [6] is roughly as follows:

- Read or write a situation of consideration

- Ask students to write down what they will do in this situation.

- Seek a suggestive action plan or collect answers

- Invite a group of students who have similar reactions to play a role-playing situation

- Inspire the whole class to comment on the reaction of the role-player

- If the students still have interest, they can continue to play and discuss the further reaction from the students.

\section{- Teacher and student summary together}

It can be seen that in the implementation procedure, basic theoretical viewpoints run through the consideration model, reflecting the characteristics of situationality, empathy, integration of emotion and rationality, and promotion morality with emotion.

In a nutshell, the consideration model takes moral emotions as the entry point and main line, with the goal of learning to care to build a set "four-dimensional integration" moral education model that connects the past and the future, links organically and forms its own system on the basis of regulating the quality of teachers, method selection, teaching materials and situation setting. The basic structure of the consideration model is shown in "Fig. 1". 


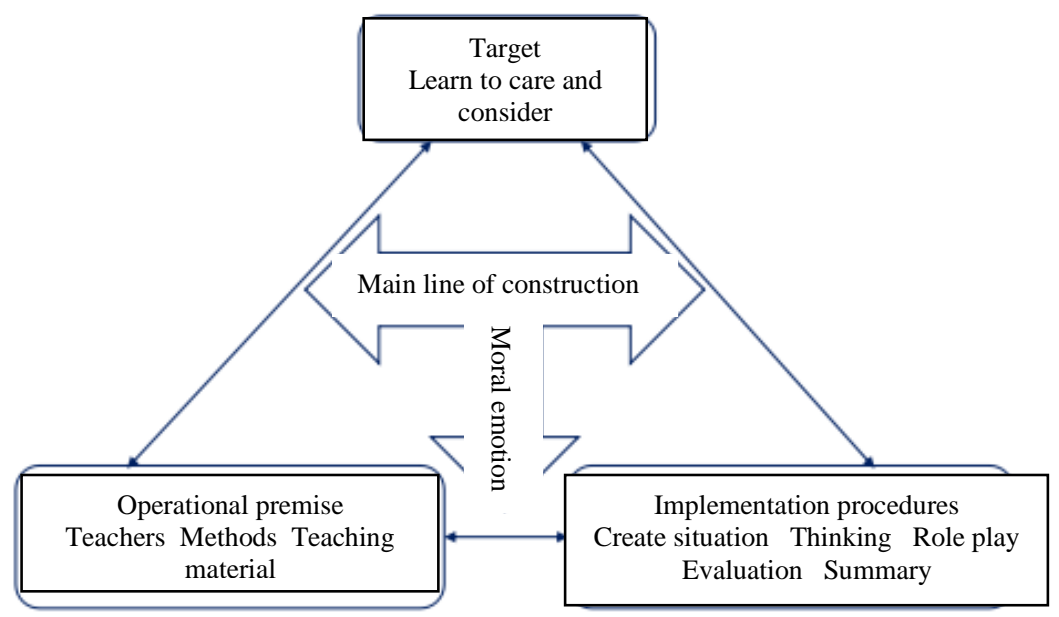

Fig. 1. The "four-dimensional integration" basic structure of the consideration model.

\section{THE ENLIGHTENMENT OF "LEARNING TO CARE" — THE MORAL EDUCATION FUNCTION OF KINDERGARTEN SOCIAL ACTIVITIES}

Mr. Chen Heqin divided the kindergarten activities into five major areas of health, science, society, language and art. Because the various activities of the kindergartens were interconnected and integrated, Chen Heqin vividly called it a five-finger activity.

The Guide for Learning and Development of Children Aged 3-6 (hereinafter referred to as the "Guide") takes the five major areas of kindergarten activities as the basic frame, and elaborates on the development standards and operational recommendations in various fields for young children. The Guide points out that children should be "willing to communicate with others", "friendly with their peers", and "care for and respect for others" in social activities [2]. The "Guidelines for Kindergarten Education" also emphasizes "enhancing self-confidence, and cultivating children's gregarious, friendly attitudes and behaviors", "friendliness", "loving parents, companions, hometown, and the motherland" in the field of social education [8]. Obviously, "respecting others and friendly communication" is a concrete manifestation of "learning to care" in the social education field of kindergarten. Subject to the fact that children's physical and mental development is not mature enough, the "learning to care" at this stage is a preliminary moral enlightenment education, which focuses on cultivating young children's pro-social behaviors with "being friendly" as their basic emotional attitude.

In a word, kindergarten education gives the moral enlightenment task of "learning to care for and considerate" to the kindergarten social activities field. Friendly communication, respect for others, and love for parents and the motherland is the specific requirements of the goal of "learning to care" for 3-6-year-old children.

\section{THE CONSIDERATION MODEL - EXPLORING THE PATH OF IMPROVING THE KINDERGARTENS SOCIAL ACTIVITIES}

Based on the above discussion, the consideration model has opened up a "four-dimensional" moral education system with morality as the main line for moral education, and the kindergarten social activities bear the responsibility of enlightenment education for children's "learning to care". A new type of moral education model can often get a new life in specific practical applications. The old moral education tends to be transformed and upgraded in the new moral education model. The consideration model may expand the territory for the development of kindergarten social education activities, and extend a new way to eliminate the stereotype of old moral education.

\section{A. Moral Indoctrination: Cognitive Moral Education Model Goes into Rigid Road}

As far as the current situation of kindergarten education activities is concerned, moral education is still taking an old road with depressed prospect: moral education adheres to the old model of All-round Doctrine, Intellectualism, indoctrination and development, so that children only master some superficial knowledge rather than realize the absorption and internalization of virtues, and moral education lacks effectiveness with a bleak future. Strengthening moral education at the level of knowledge and cognition can indeed improve the moral level of young children to a certain extent, but the monism bias of only following the "cognition" will lead the cognitive moral education model to enter the quagmire of rigidity and dogma. The abuse of moral indoctrination is the vivid representation of the cognitive moral education model going towards absolutization and extreme. "The moral education model is the improvement of the essence of moral education experience. The experience only represents the past, so when the "model" develops to a certain stage, it will become a 'stereotype'. Therefore, we cannot only follow the "model", much less the single model. "[7] The change of the modern moral education model does not mean the elimination of one 
mode and the complete reconstruction of another model. Each model has its own advantages and disadvantages. If any kind of moral education model is highly respected, the effect must be negative and harmful.

Under the enforcement of intellectualism moral education mode, the kindergarten moral education tends to be the cram and inculcation of the moral knowledge, so that the "moral" drifts away from humanity and life gradually and gets lost. Only relying on the cold moral knowledge cannot cultivate a living person with moral aura. Early childhood is the initial stage of human moral development. At this stage, moral development is likely to anchor the character trend of one's life, so it is necessary to break through and weaken the traditional moral training model and explore a path of moral education with more influence.

\section{B. Emotional Moral Education: the Consideration Model Brings New Value}

The moral education model that is absolutely rational, knowledgeable and instrumental is high-sounding, strong outwardly and weak inwardly. It lacks the warmth of humanity and the mutual care and mutual love. The virtues become unreachable and embarrassing. The consideration model with the theme of "learning to care" takes the awakening of moral emotions as main line, and integrates the temperature of human care, which will effectively break the haze of kindergarten moral indoctrination and effectively enhance the practical value of moral education.

1) Develop intrinsic motivation to meet the needs of care: The consideration model, based on humanism, holds that mutual care and understanding and being friendly with others are the inherent original motivation and basic needs of humanity development. The most important feature of the consideration model is that the way of caring is a pleasant way, and no theory can put forward such a claim in such a direct way. "[9] Children are always willing to live in harmony with others. Based on this, kindergarten social education should start from the original motives and needs of children's desire to care and be cared for, considerate and be considerate, and love and be loved, nourish and extend this kind of innate altruistic concept and then make them generate interpersonal and social consciousness, develop pro-social behaviors, and correct anti-social behaviors. As Mcphail and others believe, "self-centered, self-indulgent, selfish, rude and perverse behavior needs the help of the consideration model". [10].

The thinking and emotions of 3-6-year-old children present self-centered and egoism characteristics because of their immature development. Kindergarten life is a social collective life, as well as an important beginning of the secondary socialization stage of children, so exploring children's care for others and understanding the needs of others, helping young children develop their inner understanding emotions, improving the maturity of young children to help them gradually adapt to the kindergarten life may be one of the effective ways to improve kindergarten social education activities, correct the evils of traditional moral education models, and improve the moral education model of kindergartens.

2) Setting up hidden courses to create a situation of concern: The kindergarten curriculum is divided into two categories: explicit curriculum and hidden curriculum. Because the development level of children's random attention and abstract thinking ability is not high, and moral education has the characteristics of comprehensiveness, potential and delayed nature, the social moral education activities of kindergartens should be carried out mainly through hidden courses. By creating an atmosphere of mutual understanding and care in kindergartens and classes, and strengthening the virtues of kindergarten life situations, children's moral emotions are stimulated to promote the growing of their "care" emotions.

"Since the 1970s, there has been a 'paradigm shift' from the exploration of universal education law to seeking contextualized education." [11] "The ontology of education has shifted from the knowledge ontology to the intellectual ontology and then to the humanity ontology."[12] The consideration model believes that "care" and "consideration" are the inherent needs of human nature. It regards situational creation and influence as the main way of moral education, and also includes role-playing and discussion activities into the specific operational categories of the consideration model. Young children are rich in emotion and willing to play and express. Kindergarten social education activities should "create the classroom environment, campus environment and social education environment that conform to care",[5] so that children can achieve the effect of "empathy" and "emotional resonance" through the role exchange experience, which allows them to sublimate the human nature of "care" on the basis of mutual exchange and experience exchange.

3) Paying attention to model effects and guiding positive imitation: The consideration model believes that "observation learning and social imitation are irreplaceable methods of moral education" [5]. Young children in their early life like to observe and imitate others in nature. They tend to imitate and indirectly learn the words and deeds of "important others." Teachers as their models will have a subtle influence on the moral development of young children. This is in line with some of views in Bandura's "social learning theory" and the conclusions of the current brain science research on "mirror neurons".

"Teaching by example is more important than words". Kindergarten social education activities should pay attention to the potential influence of teachers' concepts and words and deeds. Teachers should stipulate themselves with high moral literacy and always pay attention to the guidance of moral demonstration on the development of children's character. They should be good example in considering and caring for others to effectively play the positive development function of the child's "respecting the teacher", and stimulate the child's ability to enhance understanding and caring for others in benign imitation. 
4) Eliminating rational overstepping and promoting the return of moral education: The consideration model opposes highly rational moral education, emphasizes the close connection between moral education and life. This is a life-based moral education model. The consideration model "is not only a moral education model, but also a life model". In the face of the danger of gradual polarization of moral intellectualism, scientism, formalism and adultism, it is necessary for moral education to re-examine its the relationship with live, break through the gloom of the rigid moral education model and take the initiative to return to humanity and living world.

This requires that kindergarten social education activities must meet the following points: on the theme of moral education, it should be organized and carried out around "care"; in the content of moral education, it should be based on the real life and practical problems of young children; in the effect of moral education, activities should enrich the moral life of young children.

5) Adhering to the integration of reason and emotion, cultivating virtue by recognition and emotion: The consideration model takes "developing the ability to understand and care" as its educational purpose. Although it emphasizes "emotion" as the basic point and main line of moral education, it does not exclude the integration and coexistence of moral cognition and moral behavior. First of all, the consideration model pays attention to fostering the inherent concern, care and understanding of human nature. It is believed that the mobilization of emotional factors is a necessary condition for the effect of moral education. Secondly, it does not ignore the importance of moral cognition, moral judgment and moral behavior and believes that the combination of knowing and understanding, and the combination of reason and emotion can achieve the virtues of human beings. Therefore, it does not pursue a single or separate understanding of morality in the knowledge, sentiment, meaning, and behavior, but has focus in multiple elements and seek common development.

\section{CONCLUSION}

Therefore, kindergarten social education activities should avoid extreme, prevent the moral education model from the extreme of knowledge infusion to the extreme of the sentimentalism, and find the relative balance with the fulcrum of "emotion" in multiple dimensions. Kindergarten social activities should not only enable children to understand moral knowledge, but also provide them with the conditions and opportunities to experience moral life, stimulate the moral feelings of "caring for others and understanding others", and lay a solid foundation for the long-term development of morality.

\section{REFERENCES}

[1] Zha Youliang. Educational Modeling [M]. Nanning: Guangxi Education Press, 1998: 3, 10.
[2] Jing Guangyi. Analysis of the construction of moral education model in contemporary schools [D]. Chengdu: Sichuan Normal University, 2003 (6): 6-10.

[3] Wang Jinyan. The Enlightenment of Moral Education "Consideration Model" to Moral Education in Chinese Universities[J]. The Guide of Science \& Education, 2010(10):146-147.

[4] Tang Hanwei. The Return of Moral Education to the Living World- The Basic Trend of Western Moral Education in the Second Half of the 20th Century[J].Journal of Inner Mongolia Normal University (Educational Science Edition), 2005(3):26-27.

[5] Feng Zengjun.A Review of the consideration Mode of Moral Education[J]. Education Research and Experiment, 1992(2):9-14.

[6] R. Hersh, J. Miller, G. Feildin. Modeld of Moral Education: An Appraisal. New York: Longman, 1980: 70.

[7] Ministry of Education. Guidelines for Learning and Development of $\begin{array}{lll}\text { Children } & \text { Aged 3-6 [EB/OL].[2012-10- }\end{array}$ 19]http://www.edu.cn/xue_qian_news_197/20121019/t20121019_858 538.shtml.

[8] Ministry of Education. Guidelines for Kindergarten Education [EB/OL].[2018-6-

10].http://www.rzps.com/Contents/Items/new503.htm.

[9] Zhang Xiaoyu. Research on the consideration model [J]. Jiangxi Social Sciences, 2001 (6): 166-168.

[10] Li Changyan. Reference from the "consideration Model" of Western Moral Education[J]. Study in Ideological Education, 2006(3): 47-48.

[11] Nell Noddings. Learning to Care - Another Model of Education [M]. Beijing: Educational Science Press, 2003 (10): 1.

[12] Zhuang Min. Reconstruction of University Moral Education Model in Social Transformation Period[J]. Guangxi Social Sciences, 2002(1): 215-217.

[13] Zhang Dajun. Educational Psychology [M]. Beijing: People's Education Press, 2004.

[14] Chen Xingjun. Early childhood education (third edition) [M]. Beijing: People's Education Press, 2010.

[15] Tan Chuanbao. Principles of Moral Education [M]. Beijing: Beijing Normal University Press, 2007.

[16] Cheng Jie, Qi Xiaoqin. Moral Dilemma [M]. Shanghai: Shanghai Science and Technology Literature Publishing House, 2016. 